\title{
Erratum to: May the wild male lose? Male wing fanning performances and mating success in wild and mass-reared strains of the aphid parasitoid Aphidius colemani Viereck (Hymenoptera: Braconidae: Aphidiinae)
}

\author{
Giovanni Benelli • Nickolas G. Kavallieratos • Elisa Donati - Margherita Mencattelli • \\ Gabriella Bonsignori · Cesare Stefanini · Angelo Canale · Russell H. Messing
}

Published online: 9 July 2014

(C) International Organization for Biological Control (IOBC) 2014

\section{Erratum to: BioControl \\ DOI 10.1007/s10526-014-9582-y}

There is an error in the title of the original publication.

The word 'loose' should read 'lose'.

The online version of the original article can be found under doi:10.1007/s10526-014-9582-y.

G. Benelli $(\bowtie) \cdot$ A. Canale $(\square)$ Insect Behaviour Group, Department of Agriculture, Food and Environment, University of Pisa, via del Borghetto 80, 56124 Pisa, Italy

e-mail: benelli.giovanni@gmail.com; g.benelli@sssup.it

A. Canale

e-mail: angelo.canale@unipi.it

N. G. Kavallieratos

Laboratory of Agricultural Entomology, Department of Entomology and Agricultural Zoology, Benaki

Phytopathological Institute, 8 Stefanou Delta str,

14561, Kifissia, Attica, Greece

E. Donati - M. Mencattelli - G. Bonsignori - C. Stefanini The BioRobotics Institute, Sant'Anna School of Advanced Studies, viale Rinaldo Piaggio 34 Pontedera, 56025 Pisa, Italy

R. H. Messing

Kauai Agricultural Research Center, University of Hawaii at Manoa, 7370 Kuamoo Rd., Kapaa, HI, USA 